\title{
CONCORRÊNCIA E DEMANDA POR TRABALHO NO BRASIL: O CASO DA COMPETIÇÃO EXTERNA
}

\author{
Cecilia Moreira Borges Loos Essinger * \\ Eduardo Pontual Ribeiro ${ }^{+}$
}

\begin{abstract}
Resumo
Mudanças no poder de mercado de empresas alteram o emprego pela mudança no nível de atividade, mas também pela alteração da sensibilidade do emprego ante a mudanças na receita. Este estudo considera o efeito do grau de competição sobre a demanda por emprego, utilizando mudanças de exposição à competição externa via variações do câmbio e da penetração das importações no Brasil. Os resultados confirmam que maior competição torna o emprego em firmais industriais mais sensível a choques de demanda. $\mathrm{O}$ efeito se verifica com variações em preços relativos (taxa de câmbio), mas não na penetração das importações.
\end{abstract}

Palavras-chave: demanda por trabalho, poder de mercado de produto, comercio internacional, Brasil.

\begin{abstract}
Changes in the market power of companies alter labor demand due to changes in the firm output and also by changes in labor revenue elasticity. This paper estimates the effect of changes in competition on labor demand, using the case of foreign competition exposure in Brazil. Our results indicate that lower competition caused by a devaluation of the exchange rate leads to a lower output labor demand elasticity, with no effect from lower import penetration.
\end{abstract}

Keywords: labor demand, product market power, international trade, Brazil.

JEL classification: F16, J23.

DOI: http://dx.doi .org/10.11606/1980-5330/ea143991

\footnotetext{
* Mestre em Economia pela UFF, Economista pelo IE/UFRJ. Economista de Furnas Centrais Elétricas S.A. c.moreiraborges@gmail.com

† Professor IE/UFRJ e Pesquisador CNPq. eribeiro@ie.ufrj.br
} 


\section{Introdução}

A relação entre as mudanças de concorrência no mercado de produto e a demanda por trabalho é um tema ainda pouco explorado entre os economistas brasileiros. A linha de pesquisa que lida, de forma indireta, sobre o assunto é a literatura sobre abertura comercial e rendimentos e abertura comercial e emprego (Gonzaga et al. (2006), Dix-Carneiro \& Kovak (2019), por exemplo). Para entender o efeito da competição externa sobre o emprego é necessário avaliar as formas com que esta competição alcança o emprego, a saber: alterações na demanda setorial, pela maior competição externa, mas também por alterações na sensibilidade do emprego à receita, ou seja, as elasticidadesemprego. Partindo em geral de modelos Hecksher-Ohlin, que embasou a análise de Gonzaga et al. (2006) para salários, as mudanças no emprego e produção são principalmente de deslocamento de demanda entre setores. Neste trabalho focamos o segundo tema, ou seja, analisar as mudanças (ou não) nas elasticidades do mercado de produto e trabalho, utilizando mudanças no grau de competição para as empresas domésticas em um setor.

Medidas usuais do grau de competição em um setor, como grau de concentração, são claramente endógenas e não permitem uma identificação do efeito da maior competição sobre o emprego (por exemplo Evans et al. (1993)). A medida escolhida para incorporar mudanças exógenas do grau de competição no Brasil advinda das importações é o câmbio. A argumentação da exogeneidade do câmbio frente a movimentos do emprego foi defendida por Guadalupe (2007) e Gourinchas (1999), por exemplo onde o segundo mostra que a taxa de câmbio responde a variáveis monetárias como diferenciais de juros e não a desequilíbrios comerciais de setores ou empresas específicas. O uso de microdados reforça esta avaliação de exogeneidade da taxa de câmbio ao emprego em cada empresa.

O câmbio pode afetar o mercado de produto doméstico, sendo esse efeito transmitido à demanda por trabalho das empresas. Pode-se pensar, de maneira bastante intuitiva, que um câmbio desvalorizado acaba protegendo o mercado nacional da concorrência externa - tudo mais constante - por tornar o produto importado relativamente mais caro para o consumidor brasileiro. Complementando a análise, consideramos também uma segunda medida de competição externa, a penetração de importações, embora esta medida possa ser endógena as empresas por depender da reação das mesmas.

Para o estudo empírico, desenvolvemos o referencial teórico com um modelo de demanda por trabalho de firmas inseridas em um ambiente de competição imperfeita e tecnologia relativamente flexível no grau de substituição entre capital e trabalho (função de produção CES). Com estas hipóteses, o grau de competição pode ser inferido a partir de mudanças na elasticidade demanda por produto das empresas. Para empresas com poder de mercado, o mark-up dos preços sobre os custos (índice de Lerner) é inversamente proporcional à elasticidade demanda por produto (Cahuc \& Zylberberg (2004), por exemplo). Neste modelo, o grau de competição irá afetar a elasticidadeproduto ou elasticidade valor da produção da demanda por trabalho, sem influenciar a elasticidade-salário condicional. Além disso, o modelo empírico reconhece que a variável de produção disponível em pesquisas industriais não é uma medida de produção física, mas sim a receita (ou valor adicionado em um modelo apenas com capital e trabalho como insumos). Isto altera a expressão da elasticidade-produto (mais precisamente valor da produção) no 
modelo empírico.

O recorte temporal escolhido de 1997 a 2008 se dá pela disponibilidade dos microdados da PIA/IBGE a partir de 1997. A análise se restringe até o ano de 2008 para isolar os efeitos da crise mundial. Estudos anteriores do efeito da concorrência internacional sobre o emprego para o Brasil, com dados anteriores a 1997, utilizam dados setoriais ou do mercado de trabalho, como pode ser visto na resenha de Arbache (2003). Em resumo, este artigo pretende avaliar os impactos das mudanças de concorrência externa no mercado de produto sobre as elasticidades da demanda por trabalho. A variável taxa de câmbio real setorial será utilizada como artifício empírico para investigar a mudança de elasticidade-produto da demanda por trabalho, uma vez que as mudanças de concorrência advindas das desvalorizações podem ser consideradas como eventos exógenos, condição necessária para a identificação dos parâmetros do modelo.

Os resultados indicam que a elasticidade-produto e elasticidade-preço exibem comportamento esperado pela teoria. A elasticidade-produto do emprego mostrou-se positiva, enquanto a elasticidade-salário foi negativa. Ambas foram estimadas no longo prazo como elásticas, sugerindo que capital e trabalho seriam gross substitutes na tecnologia e o emprego responde de forma mais que proporcional a movimentos do valor da produção. Com relação às variáveis de competição, a medida de penetração de importações não gerou efeitos significativos, além de ter o sinal contraditório com a teoria. Já o câmbio setorial teve efeito esperado e significativo, indicando que um câmbio desvalorizado, que reduz a força competitiva das importações, leva a elasticidades-produto do trabalho menores.

Este trabalho está divido em quatro partes, além desta introdução. A seção seguinte traz o arcabouço teórico que motiva e estrutura a análise. A seção posterior traz a descrição dos dados, seguido pela seção com as estimativas do modelo empírico. A última seção traz comentários finais.

\section{Demanda por trabalho e produto em um ambiente de concorrência monopolista: referencial teórico e modelo empírico}

A demanda por trabalho (representado por $L$ ) é uma demanda por insumo derivada da demanda por produto. A derivação usual da demanda por trabalho de uma empresa maximizadora de lucros supõe concorrência perfeita de produto. Já Cahuc \& Zylberberg (2004) apresentam uma versão em que a empresa possui poder de mercado de produto, inserida em um mercado de concorrência imperfeita, com equação de demanda por produto ou valor adicionado dado por $Y=\delta P^{-\eta}$, onde $\eta$ é a elasticidade-preço da demanda (em valor absoluto) e $\delta$ um termo que trata do tamanho do mercado. Em termos de demanda inversa e receita ou valor adicionado pode-se escrever, respectivamente, $P=\delta^{*} Y^{-(1 / \eta)}$ e $Y P=R=\delta * Y^{1-(1 / \eta)}$. Em um modelo mais flexível do que aquele empregado por Krishna et al. (2001), ou seja, supondo tecnologia CES (elasticidade-substituição entre insumos diferente da unidade) para capital e trabalho (com Y representando o valor adicionado), das condições de primeira ordem derivamos a equação que pode ser estimada

$$
\ln L=-\sigma w+\beta \ln R+\alpha
$$


onde $w$ é o custo marginal do trabalho. A expressão acima parece uma equação como aquela encontrada em Hamermesh (1993), onde o coeficiente $\sigma$ representa a elasticidade-substituição entre trabalho e capital, mas com algumas diferenças importantes. Inicialmente, o termo $\alpha$ incorpora deslocamentos agregados da demanda (coeficiente $\delta$ da equação da demanda) e deslocamentos de tecnologia neutra da firma (ou seja, a TFP). Mais importante, o modelo utiliza a receita da empresa como variável explicativa, ao invés de utilizar a quantidade produzida. Em geral os modelos empíricos empregados assumem que nos dados está disponível o volume produzido, mas este não é o caso da PIA e da grande maioria das pesquisas industriais.

Isto altera sobremaneira a interpretação do coeficiente associado à produção, que não mais representa apenas o inverso dos retornos à escala em um ambiente competitivo, mas uma relação não linear entre elasticidade da demanda por produto e elasticidade-substituição de insumos, a saber, $\beta=$ $(\sigma-\eta) /(1-\eta)$. Assim, um aumento da competição externa, isto é, um aumento da sensibilidade da demanda percebida pela empresa, pode levar a um aumento da elasticidade-produto dependendo do grau de substituição dos insumos. Podemos mostrar que $\partial \beta / \partial \eta=(\sigma-1) /(1-\eta)^{2}>0$ se $\sigma>1$. Importante notar que no caso da função de produção Cobb-Douglas, com $\sigma=1$, mudanças no poder de mercado e no grau de competição percebida pela empresa não alterariam o valor do coeficiente da receita no modelo. Se a elasticidadesubstituição for maior que a unidade, os insumos são ditos substitutos brutos $\left(\right.$ Cahuc \& Zylberberg 2004) ${ }^{1}$. Sabendo o valor de $\sigma$ a partir da elasticidadesalário e a elasticidade vendas na demanda por trabalho $\beta$ podemos recuperar a elasticidade-produto usando $\eta=(\beta-\sigma) /(\beta-1)$.

Grande parte da literatura estima a elasticidade-salário não condicional do emprego. Utilizando o modelo acima, esta elasticidade é dada por $\varepsilon_{L}=$ $-(1-s) \sigma-s \eta$, onde s é a parcela da receita gasta com o trabalho (e.g. Hamermesh (1993)). Assim, pode-se calcular a elasticidade-preço da demanda não condicional do insumo trabalho a partir dos resultados. Slaughter (2001) chamou a atenção de que um aumento de competição (externa) alteraria o efeito dos salários sobre o emprego pela mudança na demanda por produto $(\eta)$ ou ainda pelo acesso a tecnologias diferentes após uma liberalização comercial (que alteraria $\sigma$ ). Em nosso caso, como avaliamos o efeito do aumento de competição externa por mudanças cambiais e não por uma reforma estrutural (liberalização comercial), não consideramos o canal da mudança tecnológica. Variações cambiais são menos permanentes do que uma liberalização comercial e tornam mais arriscada uma variação na tecnologia de produção diante do horizonte necessário para tal mudança e o horizonte de um ciclo cambial.

Seguindo a literatura de demanda por trabalho, supomos a presença de custos de ajustamento para o emprego (Bond \& Van Reenen 2007), o que gera um modelo dinâmico para a demanda por emprego. A estimação utiliza dados em painel para permitir acomodar a dinâmica e controlar por fatores não observados correlacionados com explicativas. No modelo acima, no termo $\alpha$ inclui a produtividade total dos fatores da função de produção e deslocadores do tamanho do mercado. Ambos são correlacionados com o produto. Supondo

\footnotetext{
${ }^{1}$ Uma elasticidade-substituição maior que a unidade está no centro da discussão das tendências da parcela dos salários no valor adicionado e foi encontrado para os EUA em Karabarbounis \& Neiman (2014).
} 
algum tipo de barganha salarial, estes termos também serão correlacionados com o salário. Sob estas hipóteses, chegamos a expressão do modelo que será estimado:

$$
\ln L_{t}=\rho \ln L_{t-1}-\sigma \ln w_{t}+\beta \ln R_{t}+u_{i}+\mu_{t}+\xi_{i t}
$$

em que $u_{i}$ representa as características específicas da firma $i$ que não mudam no tempo, $\mu$ choques agregados deslocando a demanda por produto e $\xi_{i t}$ é o ruído branco do modelo. Estes choques agregados são medidos através de dummies de período e o termo não observado fixo no tempo $u_{i}$ eliminado pela estimação por efeitos fixos (within). O modelo dinâmico exige o uso de métodos GMM. (Wooldridge 2010). Uma questão que se coloca é a possível variação no tempo da TFP, em que ela seria incorporada no erro. Supondo choques de produtividade iid, as variáveis explicativas são apenas pré-determinadas e instrumentos precisam ser especificados para as mesmas. No contexto do método GMM, defasagens das variáveis servem como instrumentos. Por fim, dada a conhecida persistência das séries de emprego, salários e valor de vendas ou valor adicionado em dados de firmas, Bond (2002) recomenda o uso do método GMM-SYS. O modelo acima não traz defasagens nas variáveis explicativas, mas apresenta uma defasagem na variável dependente. Nas estimativas, defasagens podem ser introduzidas para acomodar possível autocorrelação dos erros.

Nosso referencial teórico indica que o grau de competição afeta o coeficiente $\beta$ na expressão (2). Quanto maior o grau de competição, maior a elasticidade-produto percebida pela empresa. Modelamos estas mudanças no coeficiente através da interação da medida de valor da produção com as medidas de competição, representadas por $Z$. Assim, o modelo estimado passa a ser

$$
\ln L_{t}=\rho \ln L_{t-1}-\sigma \ln w_{t}+\beta_{1} \ln R_{t}+\beta_{2}\left(\ln R_{t} * Z_{i t}\right)+u_{i}+\mu_{t}+\xi_{i t}
$$

A elasticidade do emprego em relação a $R$ passa a ser $\beta_{1}+\beta_{2} Z_{i t}$. Esperamos que, com um aumento da proxy de competição, a elasticidade aumente, ou seja, $\beta_{2}$ positivo.

Empregamos diferentes proxies para o grau de competição. No tocante às medidas de competição, seriam candidatos naturais e bastante intuitivos se pensar nas medidas diretas, como o índice HHI ou o coeficiente de concentração (CR4 ou outros). É necessário, contudo, observar que estas são medidas reconhecidamente endógenas (Evans et al. (1993), por exemplo), uma vez que são determinadas tanto pela demanda quanto pela competição.

No caso de bens comercializáveis, o setor externo se coloca como força competitiva relevante (Slaughter 2001). Duas proxies podem ser utilizadas para o grau de pressão competitiva das importações sobre os produtores locais. Primeiro, a penetração de importações. Esta medida é bastante usada para medir o grau de concorrência externa (Nucci \& Pozzolo 2010). Todavia pode-se argumentar que ela pode ser endógena, pois depende da reação das empresas domésticas frente a entrada de importados. Mesmo com uso de instrumentos, a associação de concentração e poder de mercado (grau de concorrência econômica) é reconhecida como fraca na literatura, por algumas razões (Evans et al. 
(1993), entre outros). Primeiro, possui fundamento teórico robusto apenas em mercados com bens homogêneos (modelo de Cournot). Segundo, o aumento das importações pode ser devido a estratégias das próprias empresas, que atuam no Brasil (o setor automobilístico é um bom exemplo de importações realizadas por produtores locais). Terceiro, a mensuração da penetração das importações como medida de concorrência supõe que os mercados estão delimitados corretamente. Dada a inevitável agregação setorial das medidas de importação, é possível que firmas individuais (nossos dados) percebam variações efetivas em sua demanda com aumento das importações (De Loecker et al. 2020). Já no caso de mudanças de preços relativos pelo câmbio, a pressão competitiva é mensurada de forma direta, via preços, e não através de concentração e se dá qualquer que seja a definição de mercado relevante ou se o produto é diferenciado ou não.

Segundo, e nosso indicador prioritário, a taxa de câmbio real bilateral. A taxa de câmbio altera preços relativos e torna produtos importados mais baratos ou caros, alterando o grau de competição do setor externo sobre as empresas domésticas. Estas mudanças são externas às empresas e a setores específicos, pois os movimentos da taxa de câmbio respondem mais a fatores financeiros do que a mudanças na balança comercial setorial. A escolha do câmbio como artifício empírico exógeno para choques de competição externa não é novidade na literatura de economia do trabalho: após o trabalho precursor de Branson and Branson \& Love (1988), seguem os trabalhos de Revenga (1992), Campa \& Goldberg (1998), Gourinchas (1999), Nucci \& Pozzolo (2010), dentre outros. Em todos eles é possível encontrar fundamentos teóricos que justificam a escolha do instrumento e garantem sua exogeneidade, condição necessária para a identificação do modelo utilizado também no presente trabalho.

Em Gourinchas (1999) tem-se uma explicação detida sobre o problema de endogeneidade no uso de taxas de câmbio como variável explicativa. O autor identifica dois possíveis motivos para a existência de exogeneidade na variável: primeiro porque a taxa de câmbio pode estar sendo afetada por mudanças na política monetária doméstica ou estrangeira, mas não devido ao comportamento da produção de empresas individuais; segundo porque o Banco Central do país irá reagir aos movimentos na taxa de câmbio nominal. Em relação ao primeiro problema identificado, o autor justifica que no longo prazo as taxas de câmbio tendem a ser estabilizadas, mas no curto e médio prazo há inúmeras evidências de que as taxas nominais de câmbio são ortogonais a choques de produtividade, escala, demanda agregada, dentre outros.

Uma idéia subjacente ao uso da penetração das importações ou da taxa de câmbio é a de que, em indústrias em que a importação é uma parcela relevante do total produzido, as firmas que tiverem maior dependência de receitas domésticas estarão mais expostas à competição externa e, com isto, ao efeito da oscilação cambial. Dito de outra forma: se a penetração de importações é alta em determinado setor, então uma apreciação da moeda nacional reduziria severamente a competitividade das firmas nacionais, tanto mais para firmas cuja produção está orientada para o mercado doméstico. Isto sugere a análise do efeito da competição externa via câmbio com uma interação com a penetração das importações. Este será uma terceira forma de medir o grau de pressão competitiva de empresas industriais inseridas em um país, mesmo com as limitações da medida de penetração das importações. 


\section{Descrição dos dados empregados}

Antes de passar para as estimativas, explicamos a organização da base de dados e estatísticas descritivas das variáveis de comércio exterior. No presente trabalho, foram utilizados microdados anuais da Pesquisa Industrial Anual (PIA-Empresa), para o período de 1997 a 2008, para as variáveis de número de pessoas ocupadas, salário médio, receita de vendas e capital. A PIA é uma pesquisa censitária para empresas industriais com 30 ou mais trabalhadores e/ou que faturaram receita bruta de sua atividade-fim acima de determinado valor $^{2}$; as demais empresas são escolhidas por seleção amostral e agrupadas em estratos finais amostrados como: 1 a 4 empregados, 5 a 9, 10 a 19 e 20 a 29. Foram excluídas da base de dados as observações do percentil 1 superior e inferior. Este corte justifica-se pela tentativa de eliminar as observações que figurem como outliers, e que potencialmente poderiam influenciar desproporcionalmente as estimativas. Além disso, foram eliminadas as observações associadas a setores que não aparecem em todos os anos, ou que são muito pouco representativas anualmente. Por fim, a presente análise ficará restrita a setores da indústria de transformação (não serão consideradas as empresas dos setores de extrativa mineral - CNAEs de 11 a 14), e aos setores compostos por menos de 4 empresas, a fim de preservar questões de confidencialidade dos microdados disponibilizados pelo IBGE.

O recorte temporal de 1997 a 2008 justifica-se. Por um lado, a relação entre abertura (1988-1995), com significativas reduções de barreiras tarifárias e não tarifárias, e salários e nível de emprego já foi exaustivamente explorada na literatura brasileira, tendo se estabelecido um consenso em torno dos seguintes resultados: a liberalização teve efeitos positivos sobre produtividade, informalidade e desemprego, conforme reforça a resenha de Arbache (2003). Desta forma, as estimativas não estarão influenciadas por este processo de abertura, pois somente serão considerados dados pós 1997. Por outro, o fim do período é balizado pelo objetivo de evitar a análise dos efeitos da crise internacional que afetou o Brasil em 2009.

As variáveis extraídas da PIA/IBGE que foram utilizadas no modelo estimado nesta seção são: número de trabalhadores ocupados, salário médio e valor bruto da transformação industrial. No âmbito da PIA, a variável de pessoal ocupado representa o total de trabalhadores efetivamente ocupados na empresa no último dia do ano de referência da pesquisa. O número médio de pessoas ocupadas no ano é calculado dividindo-se a quantidade total de pessoas ocupadas no ano pelo número de meses em que a empresa operou. Por sua vez, os salários são calculados em termos brutos, isto é, sem dedução das parcelas correspondentes às cotas de previdência social, recolhimento de imposto de renda ou quaisquer outras deduções.

A medida de produção em valor é o valor bruto da transformação industrial, medido seguindo a definição do IBGE. Os dados de salário foram deflacionados pelo Índice Nacional de Preços ao Consumidor (INPC) anual do período correspondente, já que o indicador é utilizado para medir o poder de compra dos consumidores. Já o valor da transformação industrial foi deflacionado pelo Índice de Preços por Atacado - Oferta Global Fundação Getúlio Vargas FGV (IPA-OG) por CNAE 1.0 em desagregação de três dígitos.

\footnotetext{
${ }^{2}$ Em 2010 o valor de corte foi de R $\$ 9,33$ milhões.
} 
A taxa de câmbio utilizada neste artigo foi produzida em Torracca (2011), cujo produto final foi justamente a construção desse índice, que expressa a competitividade externa dos países. É possível classificá-la como uma taxa efetiva por se tratar de uma taxa de câmbio frente a uma série de parceiros comerciais, e não uma relação bilateral, como usualmente é uma taxa de câmbio. O aspecto real dá conta de traduzir o poder de compra da moeda nacional, em contraste com a taxa nominal que expressa apenas uma relação entre unidades monetárias. Por se tratar de uma medida multilateral, na construção dessa taxa Torracca (2011) considerou a significância de cada parceiro comercial para toda a estrutura da economia doméstica brasileira.

Os dados de exportação e importação são da SECEX (Secretaria de Comércio Exterior), em desagregação CNAE 1.0 a três dígitos, com periodicidade anual e em milhares de dólares. Foi feita a conversão com base na taxa de câmbio real setorial obtida no trabalho de Torracca (2011).

Foram calculadas as penetrações de importação (Pen M) por setor CNAE 1.0 a dois dígitos, conforme metodologia sugerida por Levy \& Serra (2002). Segundo os autores, a penetração das importações pode ser calculada da seguinte forma: $P e n M=M / C A$, onde $C A=Y-(M-X)$ e $C A=$ consumo aparente; $M=$ importações; $Y=$ valor agregado ; $X=$ exportações. A Tabela 1 traz as estimativas de penetração de importações por setor dois dígitos ao longo do período de estudo.

Foi definida a variável binária trade, que assume valor 1 quando a penetração de importações é maior que 10\%. Assim, pode-se estimar, por exemplo, qual a diferença entre o efeito de uma variação cambial para os setores mais e menos expostos. A classificação de exposição do setor a variações cambiais foi feita por meio de um valor crítico do percentual de penetração de importações presente em Guadalupe (2007) e em outros estudos.

Há diferenças setoriais visíveis no patamar da penetração de importações, variando de $1 \%$ em fabricação de produtos de fumo (setor 16) a $61 \%$ no setor 33 (Manutenção e reparação de equipamentos médico-hospitalares). Mais importante para nossos objetivos, vemos significativas variações ao longo do tempo dentro de cada setor. Este tipo de variação será importante para a identificação das mudanças de elasticidades-produto devido a maior ou menor competição internacional.

Por exemplo, Fabricação de produtos de fumo (setor 16) apresentou queda pela metade da penetração de importações no período (indo de 4\% em 1996 para 2\% em 2008); desempenho semelhante foi verificado para os setores Fabricação de celulose, papel e produtos de papel (setor 21), e Fabricação de coque, refino de petróleo, elaboração de combustíveis nucleares e produção de álcool (setor 23).

Há também setores que experimentaram aumento na penetração de importações para o período, movimento oposto ao dos setores acima citados. Fabricação de produtos químicos (setor 24) e Fabricação de material eletrônico e de aparelhos e equipamentos de comunicações (setor 32) são exemplos de setores cuja competição de produtos importados exibiu aumento no período.

Em geral, percebe-se que a penetração de importações tem trajetória crescente de 1996 a 2002 na maioria dos setores. Já no biênio 2003-2004, verificase queda na penetração de importações, com recuperação a partir de 2005.

A Figura 1 traz as séries de taxa de câmbio efetiva real setorial. A Figura 1 permite algumas interpretações interessantes. Já que se tratam de taxas de câmbio efetiva real setoriais, o componente inflacionário não afeta a trajetória 
Tabela 1: Penetração de importações por setor CNAE - indústria de transformação - Brasil

\begin{tabular}{c|r|r|r|r|r|r|r|r|r|r|r|r|r}
\hline CNAE & $\mathbf{1 9 9 7}$ & $\mathbf{1 9 9 8}$ & $\mathbf{1 9 9 9}$ & $\mathbf{2 0 0 0}$ & $\mathbf{2 0 0 1}$ & $\mathbf{2 0 0 2}$ & $\mathbf{2 0 0 3}$ & $\mathbf{2 0 0 4}$ & $\mathbf{2 0 0 5}$ & $\mathbf{2 0 0 6}$ & $\mathbf{2 0 0 7}$ & $\mathbf{2 0 0 8}$ \\
\hline 15 & $6 \%$ & $6 \%$ & $6 \%$ & $6 \%$ & $5 \%$ & $7 \%$ & $4 \%$ & $3 \%$ & $4 \%$ & $3 \%$ & $3 \%$ & $6 \%$ \\
16 & $6 \%$ & $7 \%$ & $1 \%$ & $1 \%$ & $2 \%$ & $3 \%$ & $2 \%$ & $1 \%$ & $1 \%$ & $1 \%$ & $1 \%$ & $2 \%$ \\
17 & $13 \%$ & $12 \%$ & $12 \%$ & $12 \%$ & $17 \%$ & $18 \%$ & $17 \%$ & $18 \%$ & $7 \%$ & $1 \%$ & $10 \%$ & $15 \%$ \\
18 & $5 \%$ & $4 \%$ & $3 \%$ & $3 \%$ & $3 \%$ & $4 \%$ & $2 \%$ & $3 \%$ & $3 \%$ & $4 \%$ & $3 \%$ & $5 \%$ \\
19 & $9 \%$ & $10 \%$ & $8 \%$ & $7 \%$ & $8 \%$ & $10 \%$ & $7 \%$ & $7 \%$ & $8 \%$ & $9 \%$ & $8 \%$ & $12 \%$ \\
20 & $4 \%$ & $5 \%$ & $3 \%$ & $4 \%$ & $3 \%$ & $7 \%$ & $2 \%$ & $2 \%$ & $2 \%$ & $2 \%$ & $2 \%$ & $3 \%$ \\
21 & $6 \%$ & $7 \%$ & $6 \%$ & $5 \%$ & $5 \%$ & $4 \%$ & $3 \%$ & $4 \%$ & $8 \%$ & $1 \%$ & $4 \%$ & $3 \%$ \\
22 & $4 \%$ & $4 \%$ & $3 \%$ & $3 \%$ & $3 \%$ & $4 \%$ & $2 \%$ & $1 \%$ & $1 \%$ & $1 \%$ & $1 \%$ & $2 \%$ \\
23 & $7 \%$ & $5 \%$ & $6 \%$ & $6 \%$ & $7 \%$ & $5 \%$ & $3 \%$ & $3 \%$ & $3 \%$ & $4 \%$ & $3 \%$ & $5 \%$ \\
24 & $17 \%$ & $18 \%$ & $19 \%$ & $20 \%$ & $21 \%$ & $26 \%$ & $20 \%$ & $19 \%$ & $19 \%$ & $19 \%$ & $19 \%$ & $27 \%$ \\
25 & $10 \%$ & $11 \%$ & $11 \%$ & $10 \%$ & $11 \%$ & $15 \%$ & $8 \%$ & $9 \%$ & $9 \%$ & $9 \%$ & $9 \%$ & $14 \%$ \\
26 & $6 \%$ & $5 \%$ & $5 \%$ & $5 \%$ & $6 \%$ & $7 \%$ & $5 \%$ & $5 \%$ & $6 \%$ & $5 \%$ & $4 \%$ & $7 \%$ \\
27 & $16 \%$ & $17 \%$ & $15 \%$ & $17 \%$ & $16 \%$ & $18 \%$ & $9 \%$ & $8 \%$ & $10 \%$ & $10 \%$ & $10 \%$ & $17 \%$ \\
28 & $7 \%$ & $7 \%$ & $8 \%$ & $7 \%$ & $8 \%$ & $10 \%$ & $8 \%$ & $8 \%$ & $7 \%$ & $7 \%$ & $7 \%$ & $9 \%$ \\
29 & $35 \%$ & $35 \%$ & $38 \%$ & $34 \%$ & $35 \%$ & $39 \%$ & $32 \%$ & $30 \%$ & $31 \%$ & $31 \%$ & $28 \%$ & $39 \%$ \\
30 & $48 \%$ & $53 \%$ & $56 \%$ & $35 \%$ & $54 \%$ & $53 \%$ & $44 \%$ & $42 \%$ & $46 \%$ & $57 \%$ & $33 \%$ & $36 \%$ \\
31 & $27 \%$ & $27 \%$ & $34 \%$ & $32 \%$ & $38 \%$ & $40 \%$ & $30 \%$ & $27 \%$ & $21 \%$ & $26 \%$ & $25 \%$ & $32 \%$ \\
32 & $36 \%$ & $38 \%$ & $44 \%$ & $46 \%$ & $46 \%$ & $47 \%$ & $46 \%$ & $44 \%$ & $50 \%$ & $51 \%$ & $46 \%$ & $57 \%$ \\
33 & $48 \%$ & $49 \%$ & $49 \%$ & $49 \%$ & $55 \%$ & $61 \%$ & $52 \%$ & $52 \%$ & $51 \%$ & $51 \%$ & $47 \%$ & $59 \%$ \\
34 & $17 \%$ & $19 \%$ & $23 \%$ & $21 \%$ & $21 \%$ & $25 \%$ & $14 \%$ & $13 \%$ & $13 \%$ & $13 \%$ & $13 \%$ & $19 \%$ \\
35 & $22 \%$ & $24 \%$ & $24 \%$ & $43 \%$ & $28 \%$ & $41 \%$ & $18 \%$ & $17 \%$ & $18 \%$ & $23 \%$ & $16 \%$ & $28 \%$ \\
36 & $8 \%$ & $7 \%$ & $6 \%$ & $6 \%$ & $6 \%$ & $7 \%$ & $5 \%$ & $6 \%$ & $6 \%$ & $6 \%$ & $8 \%$ & $12 \%$ \\
\hline
\end{tabular}

Nota: cálculos dos autores baseado em dados brutos SECEX e PIA/IBGE.

Descrição sintética dos setores: 15 - Alimentos e Bebidas; 16 - Fumo ; 17 - Têxteis;

18 - Vestuário; 19 - Calçados e Couro; 20 - Prod. Madeira; 21 - Celulose e Papel;

22 - Impressão; 23 - Refino Combustíveis; 24 -Químicos; 25 - Borracha e plásticos;

26 - Min. Não Metálicos; 27 - Metalurgia; 28 - Prod. Metal; 29 - Máq. e

Equipamentos; 30 - Informática; 31 - Mat. Elétricos; 32 - Mat. Eletrônicos; 33 -Eq.

Médico-Hospitalar; 34 Veículos; 35 - Equip. Transporte; 36 - Móveis

das taxas exibidas, o que se traduz em uma série bem mais suavizada que a taxa de câmbio nominal. Vale notar que, para o início da série, em alguns setores as taxas de câmbio tiveram comportamentos bem diferentes da maioria. Há pelo menos 5 setores com um pico de desvalorização (alta na taxa de câmbio) em 2000, enquanto alguns outros sofrem queda nessa taxa real. A despeito desse comportamento desencontrado dos setores até 2002, deste ano em diante há um padrão bem interessante de valorização que se estende praticamente até o fim da série. Se por um lado após 2002 as séries tendem a caminhar de forma próxima, por outro é importante notar que as diferenças de câmbio setorial entre séries em uma data podem chegar a $20 \%$, como em 2009. Mais uma vez vemos nas séries uma variabilidade setorial que irá auxiliar na identificação dos efeitos da competição externa no emprego.

\section{Estimativas do modelo empírico}

Os resultados obtidos pela estimação das equações (1) a (3) foram organizados de maneira crescente quanto ao grau de complexidade do modelo estimado, partindo-se, portanto, dos Mínimos Quadrados Ordinários (OLS), passando pelo Modelo de Efeito Fixo (FE) até chegar aos modelos dinâmicos (GMM). Os modelos também foram estimados incluindo controles adicionais de indicadores de competição externa.

Inicialmente, foi estimada uma versão empírica de (2), onde o (log) emprego depende do valor bruto da transformação industrial (R) e do (log) salário(W). É reconhecido, porém, que estas estimativas são enviesadas devido, 
Figura 1: Taxas de câmbio real setorial $(2005=100)$, por CNAE 1.0 a 2 dígitos

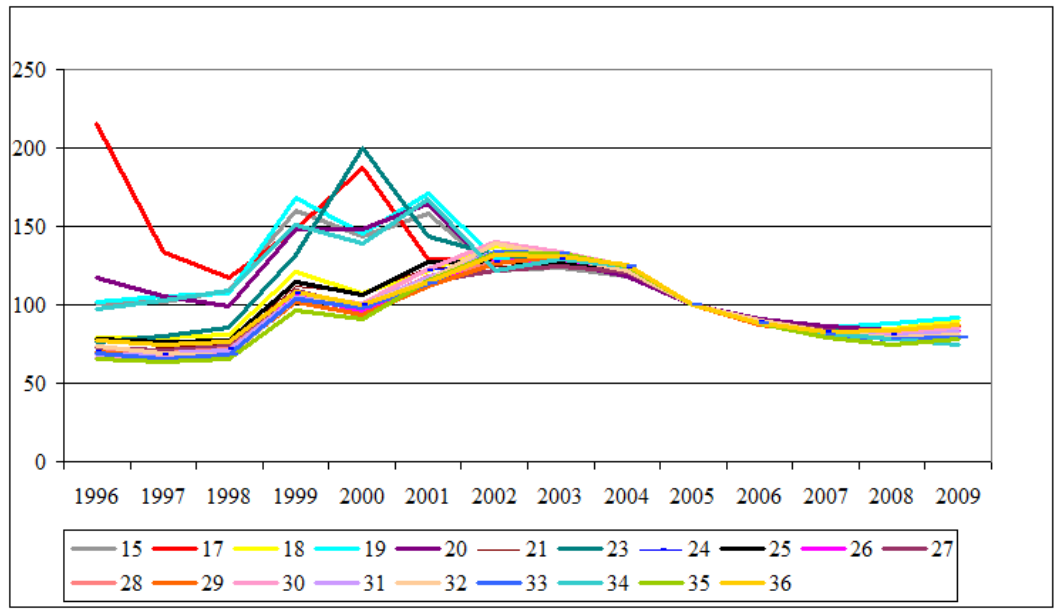

Fonte: Cálculo dos autores, baseado em Torracca (2011). Descrição sintética dos setores: 15 - Alimentos e Bebidas; 16 - Fumo ; 17 - Têxteis; 18 - Vestuário; 19 Calçados e Couro; 20 - Prod. Madeira; 21 - Celulose e Papel; 22 - Impressão; 23 Refino Combustíveis; 24 -Químicos; 25 - Borracha e plásticos; 26 - Min. Não Metálicos; 27 - Metalurgia; 28 - Prod. Metal; 29 - Máq. e Equipamentos; 30 Informática; 31 - Mat. Elétricos; 32 - Mat. Eletrônicos; 33 -Eq. Médico-Hospitalar; 34 Veículos; 35 - Equip. Transporte; 36 - Móveis.

principalmente, à endogeneidade das variáveis salário e produção, a qual é amplamente descrita na literatura.

O objetivo destas estimativas é servir de base para comparação e avaliação dos controles e instrumentos introduzidos nas especificações que se seguem. Pode-se notar que as estimativas para os coeficientes de ambas as variáveis vão gradativamente se reduzindo ao passar da estimação OLS para FE e, posteriormente, corrigindo-se para autocorrelação dos erros (FE-AR).

Pela Tabela 2 abaixo, nota-se que há uma correlação positiva entre o valor bruto da transformação industrial e demanda por trabalho nas três estimativas (MQO, Efeitos Fixos, Ef.Fixos - AR), que se reduz gradualmente nesta ordem. Se o valor da produção aumenta em $1 \%$, o nível de emprego aumenta em $0,695 \%$ na primeira estimativa. Este impacto é reduzido com uso dos efeitos fixos e considerando a autocorrelação dos erros (passa para $0,45 \%$ ). Para o salário, como esperado, o efeito é negativo, entretanto não é modificado de forma significativa de uma especificação para outra. O aumento de $1 \%$ da folha salarial como proporção do pessoal ocupado reduz em $0,54 \%$ o nível de emprego em média de acordo com estas estimativas.

A Tabela 3 abaixo traz as estimativas através do método GMM-SYS para acomodar o uso da variável explicativa defasada e a possível endogeneidade das explicativas. Os modelos ainda não trazem efeitos da concorrência externa sobre a elasticidade valor da produção e servem para entender o efeito das diferentes hipóteses de exogeneidade das explicativas sobre as elasticidades produto e salário.

Partimos de hipóteses mais restritivas sobre a exogeneidade das explicativas (estritamente exógenas nas colunas identificadas com 1) para menos restritivas, supondo apenas que as séries de valor do produto (VBTI) e custo médio 
Tabela 2: Modelos estáticos de demanda por emprego industrial

\begin{tabular}{l|c|c|c}
\hline & OLS & Efeitos Fixos & Ef.Fixos - AR \\
\hline Valor Produção t & $\begin{array}{c}0.695^{* * *} \\
(0.001)\end{array}$ & $\begin{array}{c}0.536^{* * *} \\
(0.001)\end{array}$ & $\begin{array}{c}0.455^{* * *} \\
(0.002)\end{array}$ \\
\hline Salário Médio t & $\begin{array}{c}-0.548^{* * *} \\
(0.002)\end{array}$ & $\begin{array}{c}-0.547^{* * *} \\
(0.002)\end{array}$ & $\begin{array}{c}-0.545^{* * *} \\
(0.002)\end{array}$ \\
\hline $\mathrm{R}^{2}$ & 0.746 & 0.470 & \\
\hline $\mathrm{F}$ (p-valor) & 0.000 & 0.000 & 0.000 \\
\hline Observações & 299.226 & 299.226 & 211.767 \\
\hline
\end{tabular}

Nota: Variável dependente Emprego. Todas variáveis em log. Fonte: Estimativas dos autores baseado em microdados primários da PIA/IBGE 1997-2008; elaboração própria.

do trabalho (salário médio por trabalhador) sejam pré-determinadas (colunas 2, 3, 4 e 5). Defasagens das explicativas foram empregadas para acomodar a autocorrelação, sendo esta identificada nos resíduos através de testes de especificação. O número de instrumentos em todos os modelos é restrito a até duas defasagens para não termos muitos instrumentos por período. Infelizmente, em várias situações o número de instrumentos é relativamente grande, o que leva ao teste de Sargan a ter propriedades negativas de tender a rejeitar a hipótese nula mesmo que verdadeira (baixo poder).

A parte de baixo da tabela traz ainda estimativas das elasticidades valor da produção de longo prazo do emprego $(\beta)$; elasticidade condicional de salário $(-\sigma)$, que é a elasticidade-substituição entre capital e trabalho; a elasticidade de demanda por produto implícita $(\eta)$; e a elasticidade incondicional de salário $\left(\varepsilon_{L}\right)$. Enquanto as elasticidades de longo prazo são obtidas através da expressão usual, por exemplo $\beta=\beta_{1} /(1-\rho)$, para um modelo sem defasagens do valor da produção e uma defasagem do emprego, por exemplo, coluna GMMSYS1, as estimativas da elasticidade da demanda e não condicional dos salários são obtidas através das expressões $\eta=(\beta-\sigma) /(\beta-1)$ e de $\varepsilon_{L}=-(1-s) \sigma-s \eta$, respectivamente, usando uma parcela média do emprego nos custos de $0,25^{3}$.

De maneira geral, a maior parte dos resultados da Tabela 3 se mostram significativos estatisticamente, com desvios padrões pequenos. Os coeficientes da dependente defasada e do valor da produção e emprego tendem a aumentar com a melhora na especificação, ou seja, ao considerar as explicativas contemporaneamente correlacionadas (GMM SYS 3, 4 ou 5) e mais defasagens para acomodar a autocorrelação dos erros. O teste de sobreidentificação de Sargan aponta alguma possível má especificação pelos instrumentos não serem válidos, mas o grande número de defasagens deixa o teste com tendência a rejeitar a hipótese nula de ausência de má especificação.

$\mathrm{O}$ ajuste do emprego se torna mais lento à medida que usamos instrumentos para acomodar a autocorrelação, chegando o coeficiente autocorrelacionado do emprego a 0,84 . As elasticidade valor da produção $(\beta)$ e condicional de salário do emprego $(-\sigma)$ aumentam à medida que passamos para as colu-

\footnotetext{
${ }^{3}$ A parcela do gasto com trabalho no valor adicionado é de cerca de $13 \%$ em nossos dados. Como há poder de mercado, a parcela do gasto com trabalho nos custos $s$ é dada por $s=\omega 0,13$, onde $\omega$ é a razão entre preço e custo (markup). Veja por exemplo, Cahuc \& Zylberberg (2004). Usamos um markup de aproximadamente 2, ou seja, implicitamente uma elasticidade-produto de -2 . Se empregarmos uma elasticidade-produto de -5 , a parcela nos custos seria de 0,16 , um valor menor, reduzindo a elasticidade-salário.
} 
Tabela 3: Estimativas Modelo Demanda por Trabalho - Indústria - Brasil 1997-2008.

\begin{tabular}{|c|c|c|c|c|c|}
\hline & $\begin{array}{c}\text { GMM SYS } \\
1\end{array}$ & $\begin{array}{c}\text { GMM SYS } \\
2\end{array}$ & $\begin{array}{c}\text { GMM SYS } \\
3\end{array}$ & $\begin{array}{c}\text { GMM SYS } \\
4\end{array}$ & $\underset{5}{\text { GMM SYS }}$ \\
\hline Emprego t-1 & $\begin{array}{l}0,052^{\text {*** }} \\
(0,01)\end{array}$ & $\begin{array}{l}0,518^{* * *} \\
(0,01)\end{array}$ & $\begin{array}{l}0,660^{* * *} \\
(0,01)\end{array}$ & $\begin{array}{l}0,830^{* * *} \\
(0,02)\end{array}$ & $\begin{array}{l}0,834^{* * *} \\
(0,04)\end{array}$ \\
\hline Emprego t-2 & & $\begin{array}{l}0,089^{* * *} \\
(0,01)\end{array}$ & $\begin{array}{l}0,046^{\text {***x }} \\
(0,01)\end{array}$ & $\begin{array}{l}0,014 \\
(0,01)\end{array}$ & $\begin{array}{r}-0,002 \\
(0,02)\end{array}$ \\
\hline Valor Produção & $\begin{array}{l}0,686^{\text {*** }} \\
(0,01)\end{array}$ & $\begin{array}{l}0,381^{* * *} \\
(0,01)\end{array}$ & $\begin{array}{l}0,598^{* * *} \\
(0,02)\end{array}$ & $\begin{array}{l}0,802^{* * *} \\
(0,03)\end{array}$ & $\begin{array}{l}0,799^{* * *} \\
(0,03)\end{array}$ \\
\hline $\begin{array}{l}\text { Valor Produção } \\
\text { t-1 }\end{array}$ & & & $\begin{array}{c}-0,327^{* * *} \\
(0,01)\end{array}$ & $\begin{array}{l}-0,644^{* * *} \\
(0,03)\end{array}$ & $\begin{array}{c}-0,631^{* * *} \\
(0,05)\end{array}$ \\
\hline $\begin{array}{l}\text { Valor Produção } \\
\text { t-2 }\end{array}$ & & & & & $\begin{array}{r}-0,007 \\
(0,02)\end{array}$ \\
\hline Salário Médio t & $\begin{array}{l}-0,749^{* * *} \\
(0,01)\end{array}$ & $\begin{array}{l}-0,713^{* * *} \\
(0,01)\end{array}$ & $\begin{array}{l}-0,581^{* * *} \\
(0,03)\end{array}$ & $\begin{array}{c}-0,752^{* * *} \\
(0,06)\end{array}$ & $\begin{array}{c}-0,750^{* * *} \\
(0,08)\end{array}$ \\
\hline $\begin{array}{l}\text { Salário Médio } \\
\mathrm{t}-1\end{array}$ & & & $\begin{array}{l}0,186^{* * *} \\
(0,01)\end{array}$ & $\begin{array}{l}0,493^{* * *} \\
(0,05)\end{array}$ & $\begin{array}{l}0,542^{* * *} \\
(0,07)\end{array}$ \\
\hline $\begin{array}{l}\text { Salário Médio } \\
t-2\end{array}$ & & & & & $\begin{array}{l}-0,032^{* * *} \\
(0,02)\end{array}$ \\
\hline Sargan & 0,000 & 0,000 & 0,000 & 0,000 & 0,000 \\
\hline AR 1 (p-valor) & 0,000 & 0,000 & 0,000 & 0,000 & 0,000 \\
\hline AR 2 (p-valor) & 0,000 & 0,0709 & 0,000 & 0,000 & 0,000 \\
\hline AR 3 (p-valor) & 0,000 & 0,441 & 0,793 & 0,557 & 0,629 \\
\hline No. Instrum. & 55 & 43 & 92 & 89 & 62 \\
\hline Elast LP VA $(\beta)$ & 0.72 & 0.97 & 0.92 & 1.01 & 0.96 \\
\hline Elast LP W $(-\sigma)$ & -0.79 & -1.82 & -1.34 & -1.66 & -1.42 \\
\hline $\begin{array}{l}\text { Elast Produto } \\
(|\eta|)\end{array}$ & 0.24 & 27.49 & 5.14 & -77.85 & 12.27 \\
\hline $\begin{array}{l}\text { Elast W não } \\
\text { cond }\left(\varepsilon_{L}\right)\end{array}$ & -0.65 & -8.23 & -2.29 & 18.22 & -4.13 \\
\hline
\end{tabular}

Notas: cálculos dos autores baseado em dados brutos PIA/IBGE. GMM SYS1 supondo exogeneidade estrita de salário e valor da produção; GMM SYS2 supondo exogeneidade estrita de salário e valor da produção e instrumentos defasados em até $2^{\text {a }}$ ordem ( $\mathrm{t}$-1 e t-2); GMM SYS3 - supondo correlação contemporânea de salário e valor da produção e instrumentos defasados em até $2^{\mathrm{a}}$ ordem (t-1 e t-2); GMM SYS4 - supondo correlação contemporânea de salário e valor da produção e instrumentos defasados em t-2 e t-3 (para acomodar autocorrelação de $2^{\mathrm{a}}$ ordem); GMM SYS5 - supondo correlação contemporânea de salário e valor da produção e instrumentos defasados em t-3 e t- 4 (para acomodar autocorrelação de $2^{\mathrm{a}}$ ordem); ${ }^{*}{ }^{* *}$, ${ }^{* * *}$ significativo a $10 \%, 5 \%$ e $1 \%$, respectivamente. Constante omitida da tabela. Número de observações 204783 para GMM SYS1 e 153729 para outras colunas 
nas à direita na tabela, sugerindo um viés de subestimação das elasticidades em modelos supondo exogeneidade das explicativas. A elasticidades valor da produção flutua em torno da unidade e a elasticidade condicional de salário do emprego é maior do que a unidade. Para a segunda elasticidade, isto sugere que emprego e capital seriam substitutos brutos na indústria de transformação no Brasil. A elasticidade da demanda por produto $(\eta)$ flutua bastante, dada a proximidade da elasticidade valor da produção da unidade. A combinação de uma elasticidade-substituição maior que a unidade com uma elasticidade valor da produção também maior do que a unidade gera o resultado contraditório de uma elasticidade demanda de produto $(\eta)$, em valor absoluto, negativa para GMM-SYS4. No modelo GMM-SYS3 a estimativa da elasticidade da demanda fica próxima de 5, valor utilizado em Hsieh \& Klenow (2009) para suas estimativas. Por fim, a elasticidade-salário do trabalho não condicional $\left(\varepsilon_{L}\right)$ de longo prazo é maior que a unidade, indicando uma demanda por emprego bastante sensível ao custo do trabalho ${ }^{4}$.

As Tabelas 4, 5 e 6 repetem as especificações das equações acima, incluindo diferentes proxies para competição externa. Na Tabela 4 , temos a medida de penetração das importações, interagindo com o valor do produto, para que a elasticidade valor da produção da demanda por emprego varie de acordo com o grau de competição externa. Na Tabela 5 utilizamos como medida de competição externa a taxa de câmbio setorial. Vale lembrar que a interpretação da mesma é oposta ao da Tabela 4 . Um aumento da taxa de câmbio reflete uma redução do grau de competição externa. Isto está associado, em nosso modelo, a um aumento da elasticidade-preço da demanda do produto percebida pelas empresas. De acordo com o nosso modelo teórico esperamos um coeficiente negativo desta variável de câmbio real. Por fim, na Tabela 6 temos uma especificação ajustada da taxa de câmbio, onde ela é considerada apenas para os setores com penetração das importações maior do que 10\% (nos outros setores a variável de câmbio é igual a zero. Este recorte é dado pela análise da Tabela 1 acima. Esperamos um efeito mais preciso ou maior da competição externa sobre a elasticidade receita de demanda por trabalho pelas empresas industriais.

Na Tabela 4 temos as estimativas com penetração das importações como variável explicativa. Para estes modelos, os coeficientes de emprego defasado, valor da produção e salários médios mudam pouco. A variável de penetração das importações não é significativa em nenhuma das estimativas, além de ter o sinal inesperado. Pelo referencial teórico, uma maior competição, vinda de maior penetração das importações, deveria aumentar o coeficiente do valor da produção. Na parte de baixo da tabela apresentamos, além das estimativas das elasticidades estruturais do modelo, como na Tabela 4, as elasticidades valor

\footnotetext{
${ }^{4}$ A combinação de elasticidade demanda de produto relativamente grande e de sinal contraditório à teoria em GMM-SYS4 também gera uma elasticidade-salário não condicional da demanda por trabalho de sinal contrário à teoria, destoando das estimativas em GMM-SYS2, GMM-SYS3 e GMM-SYS5. Comparando as estimativas, vemos que, enquanto a elasticidade de longo prazo ( $\beta$ ) não varia muito entre estimativas GMM-SYS2-5, ficando próximo a 1 (entre 0,92 e 1,01), em GMM-SYS4, temos o coeficiente apenas 0,01 maior que 1 e uma elasticidade-substituição maior do que 1 , gerando a elasticidade demanda de mercado de sinal contraditório à teoria. Interessante notar que, se o coeficiente do emprego defasado de GMM-SYS4 passar de 0,830 para 0,825, a elasticidade-produto passa a ter o sinal correto e resultados muito similares a GMM-SYS2. Há uma instabilidade das estimativas da elasticidade de mercado e, daí, da elasticidade-salário da demanda por trabalho quando o efeito de longo prazo do valor adicionado da produção ultrapassa, por pequeno valor, a unidade, pela combinação de coeficientes e a estrutura do modelo.
} 
da produção para o emprego para diferentes valores da penetração das importações. Como o coeficiente desta última variável é pequeno e não significativo, as estimativas não se alteram com mudanças na penetração das importações. De qualquer forma, é interessante notar que o teste de Sargan não aponta a possibilidade de má especificação do modelo para os modelos GMM-SYS 4 e 5. A baixa capacidade da penetração das importações de conseguir distinguir mudanças de competição ao longo do tempo pode ser esperada, dada a discussão na seção 2 .

A Tabela 5 traz os resultados para a variável de taxa de câmbio interagida com a variável de valor da produção da firma, principal ferramenta para introduzir mudanças na competição externa a ser testado no presente artigo. De forma sistemática, os resultados se mostram estatisticamente significativos, negativos e situados no intervalo $-0,0444$ e $-0,0084$. O sinal do coeficiente é o esperado: um aumento da taxa de câmbio reduz a força competitiva das importações para as firmas de um setor estudado, pelo aumento dos preços dos importados em moeda local, reduzindo o coeficiente do valor da produção. A parte de baixo da Tabela 5 mostra como um aumento na taxa de câmbio (uma desvalorização cambial) diminui a elasticidade valor da produção para o emprego, o que é coerente com um maior poder de mercado das empresas brasileiras.

Combinando as duas variáveis de competição utilizadas acima, foi criada uma nova variável, denominada trade, que representa a taxa de câmbio apenas para os setores mais expostos, ou seja, cuja penetração de importações seja cima de $10 \%$. Esta medida tem como objetivo avaliar se houve um efeito composição que viciou as estimativas usando a taxa de câmbio para todos os setores. Se o efeito do câmbio é percebido apenas em setores onde a competição externa for mais efetiva (medida pela penetração das importações), o coeficiente do câmbio irá medir o efeito médio envolvendo setores com efeito significativo e setores com efeito nulo, pressionando para baixo o coeficiente do câmbio setorial na Tabela 5. Vimos que o efeito da penetração das importações não foi significativo quando considerado um contínuo de valores (Tabela 4), mas talvez as importações sejam concorrencialmente relevantes apenas para setores com grande penetração das importações. Uma boa proporção de setores possui tal grande penetração das importações, como vemos na Tabela 1.

Os resultados que incluem as estimativas para a variável trade (taxa de câmbio real para os setores com maior penetração das importações) estão descritos na Tabela 6. Os resultados não mudam muito em relação à Tabela 5, em grande parte devido à não significância dos coeficientes de penetração de importação, como visto na Tabela 4 . Os coeficientes das defasagens da dependente defasada aumentam marginalmente e os coeficientes das explicativas caem um pouco. A elasticidade-produto de longo prazo, por exemplo, passa de 1,19 em GMM-DIF 5 da Tabela 6 para 1,15 em GMM-DIF 5 da Tabela 6. O efeito da taxa de câmbio se mantém relevante em todos os modelos, indicando robustez da significância do efeito da competição externa (via câmbio) sobre a demanda por trabalho, lembrando que na Tabela 4 o efeito da penetração das importações foi mais fraco, não significativo. Por outro lado, como nas Tabelas 3 a 5, a combinação de elasticidade valor da produção $(\beta)$ maior que a unidade no longo prazo e elasticidade-substituição $(-\sigma)$ maior e maior do que um, em valor absoluto, gera uma elasticidade de demanda de mercado $(\eta)$ de sinal oposto à teoria, contaminando também o resultado da elasticidade- 
Tabela 4: Demanda por Trabalho e Penetração de Importações (PenM)- Indústria, Brasil 1997-2008

\begin{tabular}{|c|c|c|c|c|c|}
\hline & $\begin{array}{c}\text { GMM SYS } \\
1\end{array}$ & $\begin{array}{c}\text { GMM SYS } \\
2\end{array}$ & $\begin{array}{c}\text { GMM SYS } \\
3\end{array}$ & $\begin{array}{c}\text { GMM SYS } \\
4\end{array}$ & $\underset{5}{\text { GMM SYS }}$ \\
\hline Emprego t-1 & $\begin{array}{l}0,053^{* * *} \\
(0,01)\end{array}$ & $\begin{array}{l}0,518^{* * *} \\
(0,01)\end{array}$ & $\begin{array}{l}0,673^{* * *} \\
(0,01)\end{array}$ & $\begin{array}{l}0,837^{* * *} \\
(0,02)\end{array}$ & $\begin{array}{l}0,862^{* * *} \\
(0,04)\end{array}$ \\
\hline Emprego t-2 & & $\begin{array}{l}0,088^{* * *} \\
(0,01)\end{array}$ & $\begin{array}{l}0,049^{* * *} \\
(0,01)\end{array}$ & $\begin{array}{l}0,018^{* *} \\
(0,01)\end{array}$ & $\begin{array}{r}-0,013 \\
(0,02)\end{array}$ \\
\hline Valor Produção t & $\begin{array}{l}0,686^{* * *} \\
(0,01)\end{array}$ & $\begin{array}{l}0,382^{* * *} \\
(0,01)\end{array}$ & $\begin{array}{l}0,572^{* * *} \\
(0,02)\end{array}$ & $\begin{array}{l}0,782^{* * *} \\
(0,03)\end{array}$ & $\begin{array}{l}0,786^{* * *} \\
(0,03)\end{array}$ \\
\hline Valor Produção t-1 & & & $\begin{array}{c}-0,312^{* * *} \\
(0,01)\end{array}$ & $\begin{array}{l}-0,626^{* * *} \\
(0,03)\end{array}$ & $\begin{array}{l}-0,644^{* * *} \\
(0,05)\end{array}$ \\
\hline Valor Produção t-2 & & & & & $\begin{array}{l}0,007 \\
(0,02)\end{array}$ \\
\hline $\begin{array}{l}\text { (Valor Produção * } \\
\text { PenM) } t\end{array}$ & $\begin{array}{l}0,001 \\
(0,00)\end{array}$ & $\begin{array}{r}-0,005 \\
(0,00)\end{array}$ & $\begin{array}{l}0,003 \\
(0,01)\end{array}$ & $\begin{array}{r}-0,007 \\
(0,01)\end{array}$ & $\begin{array}{r}-0,009 \\
(0,01)\end{array}$ \\
\hline $\begin{array}{l}\text { (Valor Produção * } \\
\text { PenM t-1 }\end{array}$ & & & $\begin{array}{r}-0,001 \\
(0,00)\end{array}$ & $\begin{array}{r}-0,008 \\
(0,01)\end{array}$ & $\begin{array}{r}-0,010 \\
(0,01)\end{array}$ \\
\hline $\begin{array}{l}\text { (Valor Produção * } \\
\text { PenM) t -2 }\end{array}$ & & & & & $\begin{array}{l}0,003 \\
(0,00)\end{array}$ \\
\hline Salário Médio t & $\begin{array}{c}-0,750^{* * *} \\
(0,01)\end{array}$ & $\begin{array}{c}-0,714^{* * *} \\
(0,01)\end{array}$ & $\begin{array}{c}-0,522^{* * *} \\
(0,03)\end{array}$ & $\begin{array}{c}-0,707^{* * *} \\
(0,06)\end{array}$ & $\begin{array}{c}-0,695^{* * *} \\
(0,08)\end{array}$ \\
\hline Salário Médio $\mathrm{t}-1$ & & & $\begin{array}{l}0,172^{\text {**स }} \\
(0,01)\end{array}$ & $\begin{array}{l}0,480^{\text {*** }} \\
(0,04)\end{array}$ & $\begin{array}{l}0,547^{\text {*** }} \\
(0,07)\end{array}$ \\
\hline Salário Médio t -2 & & & & & $\begin{array}{c}-0,041^{* * *} \\
(0,01)\end{array}$ \\
\hline Sargan & 0,000 & 0,000 & 0,000 & 0,357 & 0,710 \\
\hline AR 1 (p-valor) & 0,000 & 0,000 & 0,000 & 0,000 & 0,000 \\
\hline AR 2 (p-valor) & 0,000 & 0,076 & 0,000 & 0,000 & 0,000 \\
\hline AR 3 (p-valor) & 0,000 & 0,562 & 0,748 & 0,557 & 0,759 \\
\hline No. Instrum. & 56 & 44 & 122 & 118 & 82 \\
\hline $\begin{array}{l}\text { Elast LP VA }(\beta) \\
\text { PenM=0.25 }\end{array}$ & 0,72 & 0,97 & 0,94 & 1,05 & 0,96 \\
\hline Elast LP W $(-\sigma)$ & $-0,79$ & $-1,81$ & $-1,26$ & $-1,57$ & $-1,25$ \\
\hline $\begin{array}{l}\text { Elast Prod. }(|\eta|) \\
\text { PenM }=0.25\end{array}$ & 0,24 & 24,99 & 5,05 & $-10,99$ & 7,93 \\
\hline $\begin{array}{l}\text { Elast W não } \\
\text { cond }(\varepsilon L)\end{array}$ & $-0,65$ & $-7,61$ & $-2,21$ & 1,57 & $-2,92$ \\
\hline $\begin{array}{l}\text { Penetração } \\
\text { Import. (PenM) }\end{array}$ & $\begin{array}{c}\text { Elast LP } \\
\text { VA }(\beta)\end{array}$ & $\begin{array}{c}\text { Elast LP } \\
\text { VA }(\beta)\end{array}$ & $\begin{array}{c}\text { Elast LP } \\
\text { VA }(\beta)\end{array}$ & $\begin{array}{c}\text { Elast LP } \\
\text { VA }(\beta)\end{array}$ & $\begin{array}{c}\text { Elast LP } \\
\text { VA }(\beta)\end{array}$ \\
\hline$\overline{0,05}$ & 0,72 & 0,97 & 0,94 & 1,07 & 0,99 \\
\hline 0,10 & 0,72 & 0,97 & 0,94 & 1,06 & 0,98 \\
\hline 0,20 & 0,72 & 0,97 & 0,94 & 1,05 & 0,97 \\
\hline 0,30 & 0,73 & 0,97 & 0,94 & 1,04 & 0,96 \\
\hline 0,40 & 0,73 & 0,96 & 0,94 & 1,03 & 0,95 \\
\hline 0,50 & 0,73 & 0,96 & 0,94 & 1,02 & 0,94 \\
\hline
\end{tabular}

Notas: cálculos dos autores baseado em dados brutos PIA/IBGE. GMM SYS1 - supondo exogeneidade estrita de salário e valor da produção; GMM SYS2 supondo exogeneidade estrita de salário e valor da produção e instrumentos defasados em até $2^{\mathrm{a}}$ ordem ( $\mathrm{t}-1$ e t-2); GMM SYS3 - supondo correlação contemporânea de salário e valor da produção e instrumentos defasados em até $2^{\mathrm{a}}$ ordem (t-1 e t-2); GMM SYS4 - supondo correlação contemporânea de salário e valor da produção e instrumentos defasados em t-2 e t-3 (para acomodar autocorrelação de 2a ordem); GMM SYS5 - supondo correlação contemporânea de salário e valor da produção e instrumentos defasados em t-3 e t-4 (para acomodar autocorrelação de $2^{\mathrm{a}}$ ordem); ${ }^{*},{ }^{* *},{ }^{* * *}$ significativo a $10 \%, 5 \%$ e $1 \%$, respectivamente. Constante omitida da tabela. PenM penetração das importações. Número de observações 202138 para GMM SYS1 e 151805 para outras colunas. 
Tabela 5: Demanda por Trabalho e Taxa de Câmbio Efetiva (RER)- Indústria, Brasil 1997-2008

\begin{tabular}{|c|c|c|c|c|c|}
\hline & $\begin{array}{c}\text { GMM SYS } \\
1\end{array}$ & $\begin{array}{c}\text { GMM SYS } \\
2\end{array}$ & $\begin{array}{c}\text { GMM SYS } \\
3\end{array}$ & $\begin{array}{c}\text { GMM SYS } \\
4\end{array}$ & $\begin{array}{c}\text { GMM SYS } \\
5\end{array}$ \\
\hline Emprego t-1 & $\begin{array}{l}0,050^{* * *} \\
(0,01)\end{array}$ & $\begin{array}{l}0,520^{* * *} \\
(0,01)\end{array}$ & $\begin{array}{c}0,707^{* * *} \\
(0,01)\end{array}$ & $\begin{array}{l}0,846^{* * *} \\
(0,01)\end{array}$ & $\begin{array}{l}0,870^{* * *} \\
(0,03) \\
\end{array}$ \\
\hline Emprego t-2 & & $\begin{array}{l}0,090^{* * *} \\
(0,01)\end{array}$ & $\begin{array}{l}0,059^{* * *} \\
(0,00)\end{array}$ & $\begin{array}{l}0,023^{* * *} \\
(0,01)\end{array}$ & $\begin{array}{l}0,002 \\
(0,02)\end{array}$ \\
\hline Valor Produção t & $\begin{array}{l}0,727^{* * * *} \\
(0,01)\end{array}$ & $\begin{array}{l}0,4011^{* * *} \\
(0,01)\end{array}$ & $\begin{array}{l}0,546^{\text {*** }} \\
(0,02)\end{array}$ & $\begin{array}{l}0,823^{\text {**** }} \\
(0,03)\end{array}$ & $\begin{array}{l}0,808^{\text {*** }} \\
(0,03)\end{array}$ \\
\hline Valor Produção t- & & & $\begin{array}{c}-0,292^{* * *} \\
(0,01)\end{array}$ & $\begin{array}{l}-0,653^{* * *} \\
(0,03)\end{array}$ & $\begin{array}{l}-0,660^{* * *} \\
(0,04)\end{array}$ \\
\hline Valor Produção t- & & & & & $\begin{array}{l}0,004 \\
(0,02)\end{array}$ \\
\hline $\begin{array}{l}\text { (Valor Produção* } \\
\text { RER) } t\end{array}$ & $\begin{array}{l}-0,044^{* * *} \\
(0,00)\end{array}$ & $\begin{array}{c}-0,022^{* * *} \\
(0,00)\end{array}$ & $\begin{array}{l}-0,008^{* * *} \\
(0,00)\end{array}$ & $\begin{array}{l}-0,022^{* * *} \\
(0,00)\end{array}$ & $\begin{array}{l}-0,021^{* * *} \\
(0,00)\end{array}$ \\
\hline $\begin{array}{l}\text { (Valor Produção * } \\
\text { RER) t-1 }\end{array}$ & & & $\begin{array}{l}-0,013^{* * *} \\
(0,00)\end{array}$ & $\begin{array}{r}-0,006 \\
(0,00)\end{array}$ & $\begin{array}{r}-0,006 \\
(0,00)\end{array}$ \\
\hline $\begin{array}{l}\text { (Valor Produção * } \\
\text { RER) } t-2\end{array}$ & & & & & $\begin{array}{l}0,004 \\
(0,00)\end{array}$ \\
\hline Salário Médio t & $\begin{array}{l}-0,753^{* * *} \\
(0,01)\end{array}$ & $\begin{array}{c}-0,717^{* * *} \\
(0,01)\end{array}$ & $\begin{array}{l}-0,545^{* * *} \\
(0,02)\end{array}$ & $\begin{array}{l}-0,727^{* * *} \\
(0,05)\end{array}$ & $\begin{array}{l}-0,679^{* * *} \\
(0,05)\end{array}$ \\
\hline Salário Médio t -1 & & & $\begin{array}{l}0,174^{* * *} \\
(0,01)\end{array}$ & $\begin{array}{l}0,491^{* * *} \\
(0,04)\end{array}$ & $\begin{array}{l}0,522^{* * *} \\
(0,05)\end{array}$ \\
\hline Salário Médio t -2 & & & & & $\begin{array}{l}-0,036^{* * *} \\
(0,01)\end{array}$ \\
\hline Sargan & 0,000 & 0,000 & 0,000 & 0,000 & 0,000 \\
\hline$\overline{\mathrm{AR}} 1$ (p-valor) & 0,000 & 0,000 & 0,000 & 0,000 & 0,000 \\
\hline$\overline{\mathrm{AR}} 2$ (p-valor) & 0,000 & 0,048 & 0,000 & 0,000 & 0,000 \\
\hline AR 3 (p-valor) & 0,000 & 0,478 & 0,593 & 0,490 & 0,708 \\
\hline No. Instrum. & 56 & 44 & 121 & 118 & 81 \\
\hline $\begin{array}{l}\text { Elast LP VA }(\beta) \\
\text { RER }=1.1\end{array}$ & 0.71 & 0.96 & 0.99 & 1.06 & 0.99 \\
\hline Elast LP W $(-\sigma)$ & $-0,79$ & $-1,84$ & $-1,59$ & $-1,79$ & $-1,51$ \\
\hline $\begin{array}{l}\text { Elast Prod. }(|\eta|) \\
\text { RER }=1.1\end{array}$ & 0,28 & 23,63 & 52,23 & $-11,25$ & 41,75 \\
\hline $\begin{array}{l}\text { Elast W não } \\
\text { cond }\left(\varepsilon_{L}\right)\end{array}$ & $-0,66$ & $-7,29$ & $-14,25$ & 1,47 & $-11,57$ \\
\hline $\begin{array}{l}\text { Taxa de } \\
\text { Câmbio (rer) }\end{array}$ & $\begin{array}{l}\text { Elast LP } \\
\text { VA }(\beta)\end{array}$ & $\begin{array}{l}\text { Elast LP } \\
\text { VA }(\beta)\end{array}$ & $\begin{array}{l}\text { Elast LP } \\
\text { VA }(\beta)\end{array}$ & $\begin{array}{l}\text { Elast LP } \\
\text { VA }(\beta)\end{array}$ & $\begin{array}{c}\text { Elast LP } \\
\text { VA }(\beta)\end{array}$ \\
\hline$\overline{0,80}$ & 0,73 & 0,98 & 1,02 & 1,13 & 1,04 \\
\hline$\overline{0,90}$ & 0,72 & 0,97 & 1,01 & 1,11 & 1,02 \\
\hline$\overline{1,00}$ & 0,72 & 0,97 & 1,00 & 1,09 & 1,01 \\
\hline 1,10 & 0,71 & 0,96 & 0,99 & 1,06 & 0,99 \\
\hline 1,20 & 0,71 & 0,96 & 0,98 & 1,04 & 0,97 \\
\hline 1,30 & 0,73 & 0,96 & 0,94 & 1,02 & 0,94 \\
\hline
\end{tabular}

Notas: cálculos dos autores baseado em dados brutos PIA/IBGE. GMM SYS1 - supondo exogeneidade estrita de salário e valor da produção; GMM SYS2 supondo exogeneidade estrita de salário e valor da produção e instrumentos defasados em até $2^{a}$ ordem (t-1 e t-2); GMM SYS3 - supondo correlação contemporânea de salário e valor da produção e instrumentos defasados em até $2^{\mathrm{a}}$ ordem ( $\mathrm{t}-1$ e t-2); GMM SYS4 - supondo correlação contemporânea de salário e valor da produção e instrumentos defasados em t-2 e t-3 (para acomodar autocorrelação de $2^{a}$ ordem); GMM SYS5 - supondo correlação contemporânea de salário e valor da produção e instrumentos defasados em t-3 e t-4 (para acomodar autocorrelação de $2^{\mathrm{a}}$ ordem); ${ }^{*},{ }^{* *},{ }^{* * *}$ significativo a $10 \%, 5 \%$ e $1 \%$, respectivamente. Constante omitida da tabela. RER - taxa e câmbio efetiva. Valor da taxa de câmbio efetiva padronizada tal que 2005=100. Número de observações 198225 para GMM SYS1 e 148910 para outras colunas. 
salário não condicional $\left(\varepsilon_{L}\right)$ particularmente para GMM-SYS4.

Em todos os modelos, o coeficiente negativo da variável associada à taxa de câmbio (trade) indica que uma redução da força competitiva das importações (uma desvalorização cambial, isto é, um aumento da variável trade) reduz a elasticidade da demanda por trabalho nas empresas industriais para um aumento da receita, como esperado pela teoria (vide seção 2). Estimativas para a elasticidade de longo prazo para diferentes valores do câmbio podem ser vistas na parte inferior da tabela, onde fica claro o efeito de uma desvalorização na redução da elasticidade-produto. Como chamou a atenção Slaughter (2001), por outro lado, com maior competição e maior elasticidade-produto do emprego, o emprego fica mais sensível a variações da produção. Sobre as estimativas em si, vemos na última coluna que a elasticidade é um pouco maior que a unidade, e uma valorização de $60 \%$ (passando o índice do câmbio real de 1,3 para 0,8, como visto entre 2003 e 2008 na Figura 1) altera a elasticidade de 1,04 para 1,08, uma queda relativamente pequena, mas significativa estatisticamente.

Intuitivamente, a maior elasticidade receita quando do aumento da competição (uma valorização cambial, reduzindo a variável trade) pode ser explicada da seguinte forma, lembrando que um aumento de competição comprime preços praticados no mercado interno. Se o aumento em $1 \%$ da receita se dá com simultâneo aumento da competição externa, isto indica que o aumento de receita está acompanhada de um aumento maior no volume produzido, relativo a uma situação de menor competição. Em outras palavras, um real a mais de receita traz um volume maior de produção, e com isto, emprego, em ambiente competitivo em relação a um ambiente menos competitivo.

Em síntese, as estimativas para o emprego industrial para o Brasil apontam a coerência com os resultados teóricos, ressaltando a importância do câmbio como variável relevante para mensuração da competição externa.

\section{Comentários Finais}

O presente trabalho teve como objetivo investigar se mudanças no grau de competição das empresas altera a elasticidade-produto da demanda por trabalho. Para isto, usamos mudanças na competição externa na indústria, um setor de bens comercializáveis expostos à competição internacional. Uma maior competição externa pressiona para baixo o emprego pela menor demanda de produtos domésticos, mas também pela maior sensibilidade da demanda por trabalho ao nível de produção. Este segundo efeito não é explorado na literatura nacional e pouco explorado na literatura internacional. Por exemplo Nucci \& Pozzolo (2010) e Klein et al. (2003) estudam o efeito do câmbio sobre a elasticidade-salário do emprego, não discorrendo sobre a elasticidade emprego-produção.

Como medidas de competição internacional pode-se empregar medidas diretas, como a penetração de importações, e medidas indiretas, como a taxa de câmbio. A primeira medida pode ser considerada endógena para firmas, pois depende da reação das mesmas frente à competição, na escolha de produção e preços. Já mudanças na taxa de câmbio percebida pela empresa, como fonte principal de mudança de preços relativos entre produtos domésticos e importados, aparecem exógenas à uma empresa doméstica. Para tanto, a variável taxa de câmbio real efetiva foi utilizada como canal empírico para investigar 
Tabela 6: Demanda por Trabalho e Câmbio em setores expostos (trade) Indústria, Brasil 1997-2008

\begin{tabular}{|c|c|c|c|c|c|}
\hline & $\begin{array}{c}\text { GMM SYS } \\
1\end{array}$ & $\begin{array}{c}\text { GMM SYS } \\
2\end{array}$ & $\begin{array}{c}\text { GMM SYS } \\
3\end{array}$ & $\begin{array}{c}\text { GMM SYS } \\
4\end{array}$ & $\begin{array}{c}\text { GMM SYS } \\
5\end{array}$ \\
\hline Emprego t-1 & $\begin{array}{c}0,057^{* * *} \\
(0,01)\end{array}$ & $\begin{array}{l}0,524^{* * *} \\
(0,01)\end{array}$ & $\begin{array}{l}0,682^{* * *} \\
(0,01)\end{array}$ & $\begin{array}{l}0,858^{* * *} \\
(0,02)\end{array}$ & $\begin{array}{l}0,898^{* * *} \\
(0,04)\end{array}$ \\
\hline Emprego $\mathrm{t}-2$ & & $\begin{array}{c}0,089^{* * *} \\
(0,01)\end{array}$ & $\begin{array}{c}0,054^{* * *} \\
(0,01)\end{array}$ & $\begin{array}{l}0,016^{*} \\
(0,01)\end{array}$ & $\begin{array}{r}-0,015 \\
(0,02) \\
\end{array}$ \\
\hline Valor Produção t & $\begin{array}{c}0,684^{* * *} \\
(0,01)\end{array}$ & $\begin{array}{l}0,381^{* * *} \\
(0,01)\end{array}$ & $\begin{array}{l}0,584^{* * *} \\
(0,02)\end{array}$ & $\begin{array}{l}0,797^{* * *} \\
(0,03)\end{array}$ & $\begin{array}{l}0,800^{* * *} \\
(0,03)\end{array}$ \\
\hline Valor Produção t- & & & $\begin{array}{l}-0,325^{* * *} \\
(0,01)\end{array}$ & $\begin{array}{l}-0,651^{* * *} \\
(0,03)\end{array}$ & $\begin{array}{l}-0,674^{* * *} \\
(0,05)\end{array}$ \\
\hline Valor Produção t- & & & & & $\begin{array}{l}0,008 \\
(0,02)\end{array}$ \\
\hline $\begin{array}{l}\text { (Valor Produção * } \\
\text { trade) } \mathrm{t}\end{array}$ & $\begin{array}{c}-0,018^{* * *} \\
(0,00)\end{array}$ & $\begin{array}{c}-0,017^{* * *} \\
(0,00)\end{array}$ & $\begin{array}{c}-0,013^{* * *} \\
(0,00)\end{array}$ & $\begin{array}{c}-0,026^{* * *} \\
(0,00)\end{array}$ & $\begin{array}{c}-0,030^{* * *} \\
(0,01)\end{array}$ \\
\hline $\begin{array}{l}\text { (Valor Produção * } \\
\text { trade) } \mathrm{t}-1\end{array}$ & & & $\begin{array}{l}0,008^{* * *} \\
(0,00)\end{array}$ & $\begin{array}{l}0,016^{* * *} \\
(0,00)\end{array}$ & $\begin{array}{l}0,015^{* * *} \\
(0,01)\end{array}$ \\
\hline $\begin{array}{l}\text { (Valor Produção * } \\
\text { trade) } \mathrm{t}-2\end{array}$ & & & & & $\begin{array}{l}0,006^{*} \\
(0,00)\end{array}$ \\
\hline Salário Médio t & $\begin{array}{c}-0,759^{* * *} \\
(0,01)\end{array}$ & $\begin{array}{l}-0,720^{* * *} \\
(0,01)\end{array}$ & $\begin{array}{c}-0,542^{* * *} \\
(0,03)\end{array}$ & $\begin{array}{l}-0,743^{* * * *} \\
(0,06)\end{array}$ & $\begin{array}{l}-0,778^{* * *} \\
(0,07)\end{array}$ \\
\hline Salário Médio t -1 & & & $\begin{array}{l}0,178^{\text {***F }} \\
(0,01)\end{array}$ & $\begin{array}{l}0,515^{\text {**** }} \\
(0,04)\end{array}$ & $\begin{array}{l}0,608^{\text {*** }} \\
(0,06)\end{array}$ \\
\hline Salário Médio t -2 & & & & & $\begin{array}{c}-0,040^{* * *} \\
(0,02)\end{array}$ \\
\hline Sargan & 0,000 & 0,000 & 0,000 & 0,000 & 0,000 \\
\hline$\overline{\text { AR } 1 \text { (p-valor) }}$ & 0,000 & 0,000 & 0,000 & 0,000 & 0,000 \\
\hline AR 2 (p-valor) & 0,000 & 0,048 & 0,000 & 0,000 & 0,000 \\
\hline$\overline{\text { AR 3 (p-valor) }}$ & 0,000 & 0,445 & 0,696 & 0,521 & 0,721 \\
\hline No. Instrum. & 56 & 44 & 122 & 118 & 82 \\
\hline $\begin{array}{l}\text { Elast LP VA }(\beta) \\
\text { RER }=1.1\end{array}$ & 0.70 & 0.94 & 0.96 & 1.07 & 1.06 \\
\hline Elast LP W $(-\sigma)$ & $-0,80$ & $-1,86$ & $-1,38$ & $-1,82$ & $-1,80$ \\
\hline $\begin{array}{l}\text { Elast Prod. }(|\eta|) \\
\text { RER }=1.1\end{array}$ & 0,33 & 15,49 & 11,07 & $-8,92$ & $-11,16$ \\
\hline $\begin{array}{l}\text { Elast W não } \\
\text { cond }\left(\varepsilon_{L}\right)\end{array}$ & $-0,69$ & $-5,27$ & $-3,80$ & 0,86 & 1,44 \\
\hline $\begin{array}{l}\text { Taxa de } \\
\text { Câmbio (rer) }\end{array}$ & $\begin{array}{l}\text { Elast LP } \\
\text { VA }(\beta)\end{array}$ & $\begin{array}{l}\text { Elast LP } \\
\text { VA }(\beta)\end{array}$ & $\begin{array}{l}\text { Elast LP } \\
\text { VA }(\beta)\end{array}$ & $\begin{array}{l}\text { Elast LP } \\
\text { VA }(\beta)\end{array}$ & $\begin{array}{l}\text { Elast LP } \\
\text { VA }(\beta)\end{array}$ \\
\hline$\overline{0,80}$ & 0,71 & 0,95 & 0,97 & 1,10 & 1,08 \\
\hline$\overline{0,90}$ & 0,71 & 0,94 & 0,96 & 1,09 & 1,07 \\
\hline 1,00 & 0,71 & 0,94 & 0,96 & 1,08 & 1,07 \\
\hline 1,10 & 0,70 & 0,94 & 0,96 & 1,07 & 1,06 \\
\hline 1,20 & 0,70 & 0,93 & 0,96 & 1,07 & 1,05 \\
\hline$\overline{1,30}$ & 0,70 & 0,93 & 0,96 & 1,06 & 1,04 \\
\hline
\end{tabular}

Notas: cálculos dos autores baseado em dados brutos PIA/IBGE. GMM SYS1 - supondo exogeneidade estrita de salário e valor da produção; GMM SYS2 supondo exogeneidade estrita de salário e valor da produção e instrumentos defasados em até $2^{\mathrm{a}}$ ordem (t-1 e t-2); GMM SYS3 - supondo correlação contemporânea de salário e valor da produção e instrumentos defasados em até $2^{\mathrm{a}}$ ordem (t-1 e t-2); GMM SYS 4 - supondo correlação contemporânea de salário e valor da produção e instrumentos defasados em t-2 e t-3 (para acomodar autocorrelação de $2^{\mathrm{a}}$ ordem); GMM SYS5 - supondo correlação contemporânea de salário e valor da produção e instrumentos defasados em t-3 e t-4 (para acomodar autocorrelação de $2^{\mathrm{a}}$ ordem); ${ }^{*},{ }^{* *},{ }^{* * *}$ significativo a $10 \%, 5 \%$ e $1 \%$, respectivamente. Constante omitida da tabela. Trade $=$ taxa de cãmbio efetiva (RER) para setores com penetração das importações maior do que $10 \%$ (e 0 caso contrário). Valor da taxa de cambio efetiva padronizada tal que 2005=100. Número de observações 198225 para GMM SYS1 e 148910 para outras colunas. 
essa relação. A exogeneidade do câmbio para inferir sobre mudanças no grau de competição percebida por produtores domésticos foi explorada em outros estudos, como Gourinchas (1999) e Guadalupe (2007).

O modelo empírico se baseia em um modelo teórico de uma firma que maximiza lucros em ambiente de competição imperfeita, sujeita a uma tecnologia do tipo CES. A tecnologia CES é mais flexível do que a popular tecnologia Cobb-Douglas em um ambiente de competição monopolista (Hsieh \& Klenow 2009). Este trabalho chama a atenção de que a interpretação de coeficientes em um modelo empírico de demanda por emprego com uma medida de valor agregado ou receita pode ser diferente da relação quantidade produzida $\mathrm{x}$ emprego. A quase totalidade das equações de demanda estimadas na literatura não destaca a possibilidade de que a receita deflacionada setorialmente não represente o volume vendido, pela existência de poder de mercado em setores afastados do modelo de concorrência perfeita.

Utilizamos microdados da Pesquisa Industrial Anual (PIA/IBGE) entre 1996 e 2008, período com variações significativas da taxa de câmbio real setorial, que permitirão identificar os efeitos da competição externa na demanda por trabalho. O modelo empírico reconhece a endogeneidade dos salários e produção na equação de demanda por trabalho, dada a presença de choques não observados de produtividade (Hamermesh 1993), usando estimadores GMM para dados em painel.

Em relação à estimação de uma equação de demanda por trabalho, os resultados indicam que a elasticidade-produto da demanda por trabalho e elasticidade-salário condicional exibem comportamento esperado em relação a seus sinais. A elasticidade-produto mostrou-se positiva, enquanto a elasticidadesalário foi negativa, ambas inelásticas no curto prazo e elásticas no longo prazo, com a elasticidade-substituição maior que e a unidade a elasticidade valor da produção muito próximo da unidade, com estimativas acima da unidade em vários casos. As diferentes estimativas com variáveis instrumentais apontam redução do viés de endogenia em relação a estimativas supondo exogeneidade estrita e ausência de efeitos dinâmicos, mas com ainda possíveis falhas no rol de instrumentos empregados, supondo poder relevante dos testes de especificação.

Com relação às variáveis de competição, a penetração de importações não foi significativa para o emprego industrial nos vários modelos estimados. Por outro lado, o efeito da desvalorização cambial se mostrou relevante para alterar a demanda por emprego em todas as várias especificações consideradas. Os resultados sugerem que uma desvalorização cambial (uma redução da taxa de câmbio real e uma redução da competição externa) tende a tornar a demanda por trabalho menos sensível a flutuações da receita. Com isto, confirma-se uma preocupação inicial nesta literatura de Slaughter (2001) de que maior competição (externa) torna o emprego industrial mais volátil frente a flutuações ou choques de demanda de produto nas empresas.

Algumas direções de investigação sobre o efeito da competição sobre o emprego podem ser apontadas a partir deste trabalho. Primeiro, o efeito da competição externa sobre a reorganização do emprego dentro da firma não foi levada em conta, por considerar o emprego como homogêneo. É possível que o a análise altere a composição da força de trabalho de acordo com a qualificação dos trabalhadores. Segundo, mudanças geradas por fusões e aquisições podem alterar a competição percebida pelas firmas domésticas (Gugler $\&$ Yortugku (2004), por exemplo). O desafio que se coloca no segundo caso é 
identificar fusões e aquisições de forma sistemática entre setores.

\section{Referências Bibliográficas}

Arbache, J. S. (2003), 'Comércio internacional, competitividade e mercado de trabalho: algumas evidências para o Brasil', in: Corseuil, C. H., Kume, H., eds, A abertura comercial brasileira nos anos 1990: impactos sobre emprego e salário, Rio de Janeiro: IPEA, p. 115-168, Rio de Janeiro.

Bond, S. (2002), 'Dynamic panel data models: a guide to micro data methods and practice', Portuguese Economic Journal 1((1)), 141-162.

Bond, S. \& Van Reenen, J. (2007), Microeconometric Models of Investment and Employment, Vol. 6A, New York: Elsevier.

Branson, W. \& Love, J. (1988), 'United States Manufacturing and the Real Exchange Rate', Marston, R. C., ed., Misalignment of Exchange Rates: Effects on Trade and Industry, Chicago: University of Chicago Press, p. 241-276.

Cahuc, P. \& Zylberberg, A. (2004), Labor Economics, Cambridge, MA: MIT.

Campa, J. M. \& Goldberg, L. S. (1998), 'Employment versus wage adjustment and the U.S. Dollar', The Review of Economics and Statistics 83(3), 477-489.

De Loecker, J., Eeckhout, J. \& Unger, G. (2020), 'The Rise of Market Power and the Macroeconomic Implications', Quarterly Review of Economics 135(2), 561-644.

Dix-Carneiro, R. \& Kovak, N. (2019), 'Margins of labor market adjustment to trade', Journal of International Economics 117, 125-142.

Evans, W. N., Froeb, L. M. \& Werden, G. J. (1993), 'Endogeneity in the Concentration-Price Relationship: Causes, Consequences, and Cures', The Journal of Industrial Economics . p.431-438.

Gonzaga, G., Menezes Filho, N. \& Terra, C. (2006), 'Trade liberalization and the evolution of skill earnings differentials in Brazil,', Journal of International Economics 68(2), 345-367.

Gourinchas, P. O. (1999), 'Exchange rates do matter: French job reallocation and exchange rate turbulence, 1984-1992', European Economic Review $43,1279-1316$.

Guadalupe, M. (2007), 'Product Market Competition, Returns to Skill, and Wage Inequality', Journal of Labor Economics 25(3), 439-474.

Gugler, K. \& Yortugku, G. (2004), 'The Effects of Mergers on Company Employment in the USA and Europe', International Journal of Industrial Organization 22, 481-502.

Hamermesh, D. S. (1993), Labor demand, Princeton, NJ: Princeton University Press.

Hsieh, C. T. \& Klenow, P. (2009), 'Misallocation and Manufacturing TFP in China and India', The Quarterly Journal of Economics 124(4), 1403-1448. 
Karabarbounis, L. \& Neiman, B. (2014), 'The Global Decline of the Labor Share', Quarterly Journal of Economics 129(1), 61-103.

Klein, M. W., Schuh, S. \& Triest, R. K. (2003), 'Job creation, job destruction and the real exchange rate', Journal of International Economics (59), 239-265.

Krishna, P., Mitra, D. \& Chinoy, S. (2001), 'Trade liberalization and labor demand elasticities: evidence from Turkey', Journal of International Economics 55, 391-409.

Levy, P. M. \& Serra, M. I. F. (2002), 'Coeficientes de importação e exportação na indústria. ', Boletim de Conjuntura. IPEA (n. 58).

Nucci, F. \& Pozzolo, A. F. (2010), 'The exchange rate, employment and hours: What firm-level data say?', Journal of International Economics 85, 112-123.

Revenga, A. (1992), 'Exporting jobs? The impact of import competition on employment and wages in U.S. manufacturing', Quarterly Journal of Economics 107(1), 255-284.

Slaughter, M. (2001), 'International trade and labor demand elasticities. ', Journal of International Economics 54(1), 27-56.

Torracca, J. (2011), A Evolução da Taxa de Câmbio Efetiva Real Setorial e a Mudança Estrutural do Padrão de Comércio Exterior Brasileiro. Dissertação (Mestrado em Economia da Indústria e da Tecnologia), PhD thesis, Universidade Federal do Rio de Janeiro.

Wooldridge, J. (2010), Econometric Analysis of Cross Section and Panel Data, 2a Ed, Cambridge, MA: MIT. 
